

\section{DISCLAIMER}

This report was prepared as an account of work sponsored by an agency of the United States Government. Neither the United States Government nor any agency Thereof, nor any of their employees, makes any warranty, express or implied, or assumes any legal liability or responsibility for the accuracy, completeness, or usefulness of any information, apparatus, product, or process disclosed, or represents that its use would not infringe privately owned rights. Reference herein to any specific commercial product, process, or service by trade name, trademark, manufacturer, or otherwise does not necessarily constitute or imply its endorsement, recommendation, or favoring by the United States Government or any agency thereof. The views and opinions of authors expressed herein do not necessarily state or reflect those of the United States Government or any agency thereof. 


\section{DISCLAIMER}

Portions of this document may be illegible in electronic image products. Images are produced from the best available original document. 
This work was supported by the US Department of Energy, Office of Energy Research.

Reviewed by R. Dreicer

\section{DISCLAIMER}

This report was prepared as an account of work sponsored by an agency of the United States Government. Neither the United States Government nor any agency thereof, nor any of their employees, makes any warranty, express or implied, or assumes any legal liability or responsibility for the accuracy, completeness, or usefulness of any information, apparatus, product, or process disclosed, or represents that its use would not infringe privately owned rights. References herein to any specific commercial product, process, or service by trade name, trademark, manufacturer, or otherwise, does not necessarily constitute or imply its endorsement, recommendation, or favoring by the United States Government or any agency thereof. The views and opinions of authors expressed herein do not necessarily state or reflect those of the United States Government or any agency thereof. 
LA- $-9120-M S$

UC-20f

Issued: December 1981

DE82. 010024

\title{
Preliminary Langmuir Probe Results on the CTX Gun Experiment
}

\author{
Michel Tuszewski
}
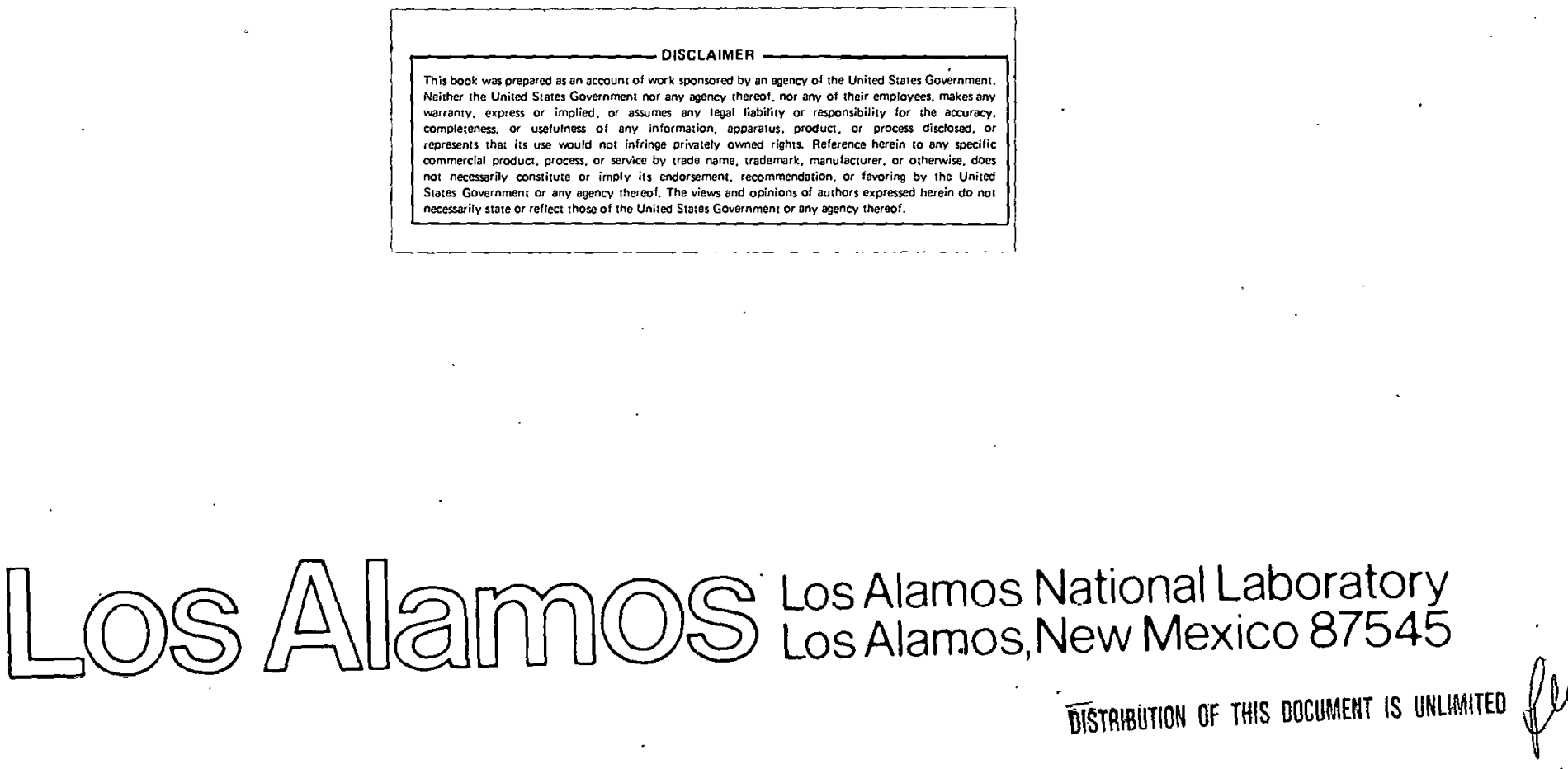


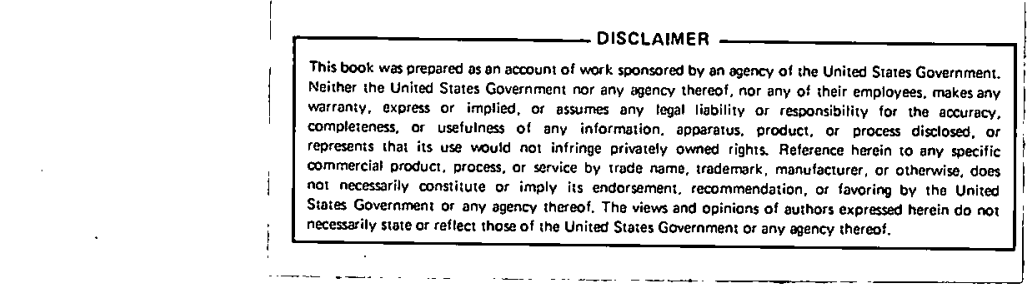

PRELIMINARY LANGMUIR PROBE RESULTS ON THE CTX GUN EXPERIMENT

by

Miche1 Tuszewsk1

\begin{abstract}
preliminary results obtained with a double Langmulr probe in the Compact Torold Experiment facility confirm the existence of a gun plasma of $\mathrm{n} \sim 5 \times 10^{14} \mathrm{~cm}^{-3}$ and $\mathrm{T} \sim 10 \mathrm{eV}$ lasting for $\sim 250-400 \mu \mathrm{s}$, which is consistent with interferometry and Thomson scattering data. The probe current characteristics as a function of voltage suggest non-Maxwellian features of the particles distribution functions.
\end{abstract}

\title{
I. INTRODUCTION
}

A Langmuir (electrostatic) probe was inserted into the flux conserver of the Compact Toroid gun experiment (CTX). Potentially, this very simple diagnostic can provide local information on the plasma fon density and electron temperature as a function of time. Spatial profiles can be obtained, shot after shot, if the plasma conditions are reproducible, and the probe may also prove useful in determining the density fluctuation level as a function of time. We describe the mechanical and electrical aspects of the probe in Sec. II, give a brief theoretical outline in Sec. III, present the experimental results in Sec. IV, and provide a summary in Sec. V. An Appendix is devoted to the interpretation of the experimental current characteristic.

\section{PROBE DESCRIPTION}

Because the gun plasma is in contact with the flux conserver, its space (or plasma) potential can be kilovolts away from the CTX tank ground or screen room ground. Indeed, a transient voltage of about $5 \mathrm{kV}$ with respect to ground and of 5 to 10-us duration was measured on the flux conserver. Therefore, it is necessary to use a double Langmuir probe with both tips floating, in order to follow the change of plasma potential as a function of time. An early attempt with a single probe proved unsuccessful. 
The probe wires were made of 4-m11-diameter tungsten and were spaced about $5 \mathrm{~mm}$ apart, outside of a pyrex envelope of 8 -mm outer diameter and $1-\mathrm{mm}$ wal1 thickness. The exposed portions of the wires were $2.5 \mathrm{~mm}$ in length, which is large compared to the wire diameter and plasma sheath diameter, so that end effects could be ignored and the one-dimensional cylindrical probe theory could be used accurately. Probes of this type, with identical tungsten wire, have been used extensively in plasmas of density $\sim 10^{14}-10^{15} \mathrm{~cm}^{-3}$, temperature $\sim 10 \mathrm{eV}$, and lifetimes of up to $1 \mathrm{~ms}$. For such plasmas, similar to those of the gun experiment, some probe current disruptions (probably unipolar arcs) are sometimes observed for bias voltages greater than about $50 \mathrm{~V}$. These disruptions have been noticed in some of the early experiments described here but disappeared almost completely after thorough degassing of the probe tips.

Figure 1(a) shows a schematic of the electrical circuit used with the

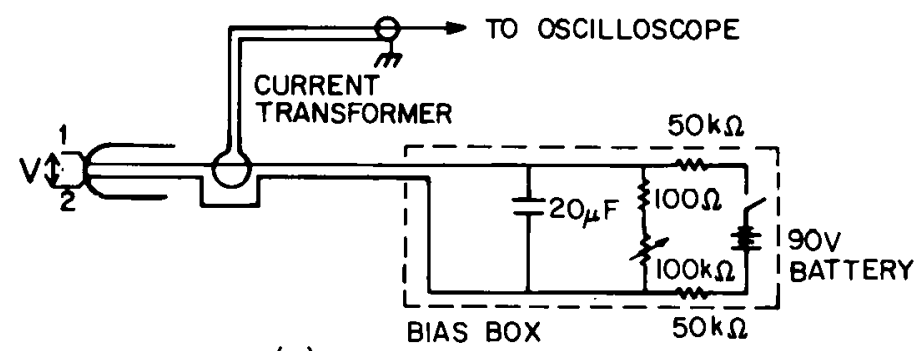

(a)

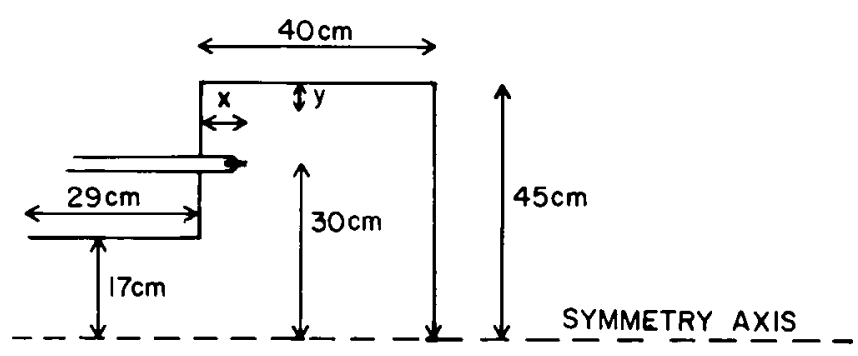

(b)

Fig. 1

(a) Probe circuit for static bias voltage; (b) Probe location with respect to the flux conserver. 
double probe. A static bias voltage $\mathrm{V}$ in the range $0-90 \mathrm{~V}$ is applied between the two tips. This should be adequate for plasma temperatures of about $10 \mathrm{eV}$. The probe wires and the blas box are floating with respect to ground, and the collected current is measured with a current transformer (Pearson probe \#411). The current loops the transformer five times so that the scope voltage calibration is $0.5 \mathrm{~V} / \mathrm{A}$. For typical ion saturation currents of about $1 \mathrm{~A}$ for about $200 \mu \mathrm{s}$, the collected charge of $2 \times 10^{-4} \mathrm{C}$ is well below the transformer 1 imlt of $0.19 \mathrm{C}$. The transformer's response time of $\sim 10 \mathrm{~ns}$ is quite adequate for these experiments. Note also that, for the above collected charge, the buffer capacitor voltage drop is less than $10 \%$.

A voltage sweeper consisting of a single capacitor discharge with peak voltage of $120 \mathrm{~V}$ and $\mathrm{RC}$ time of about 6 us was also tried. No results have been obtained as yet, because of an inftial transient voltage from the plasma to the probe wires which forced an early triggering of the sweeper.

Figure 1(b) shows the location of the probe inside the flux conserver. A 1-in. aperture in the stainless steel side wall allows the probe to move a distance $x$ inside the flux conserver. When the probe is inserted at $x=20 \mathrm{~cm}$, its distance to the center of the flux conserver is $30 \mathrm{~cm}$, as Indicated in Fig. 1(b).

\section{DOUBLE PROBE THEORY}

The double probe method was originally proposed by Johnson and Malter. ${ }^{1}$ A good theoretical treatment for such probes can be found in Chen, ${ }^{2}$ and we outline just a few key points (after Chen) in this section.

The probe used in this work is a symmetric double probe, that is, both tips have Identical collection areas $A_{p}=2 \pi r_{p} \ell_{p}$. For such probes, the voltages $V_{1}$ and $v_{2}$ on the tips are always negative with respect to the plasma (space) potential. This implies that electron collection is always impeded, electron currents are always small, and their upper bound is the lon saturation current $1_{+}$. This prevents probe damage from excessive currents but has the important disadvantage that only a few fast particles in the tail of the electron distribution can ever be collected. More precisely, for $V=0$, $v_{1}=v_{2}=v_{f}$, where $v_{f}$ is the floating potential and no net current is drawn from each tip. For a Maxwellian electron distribution in thermal equilibrium, neglecting magnetic field effects, at $\mathrm{V}=0$, the electron current $1_{\text {_ }}$ can be estimated with $(1 / 4) n e \bar{v}_{e} A_{p} e^{V_{f} / T_{e}}$, where $\bar{v}_{e}=\left(8 k T_{e} / m_{e}\right)^{1 / 2}$ and $v_{f}$ is referred 
to the space (or plasma) potential. The ion saturation current $1_{+}$is given approximately by $i_{+} \sim(1 / 4) n e \bar{v}_{1} A_{p}$, where $\bar{v}_{1}=\left(8 \mathrm{kT}_{e} / \mathrm{m}_{1}\right)^{1 / 2}$. The floating condition $1_{+}=1_{-}$yields $V_{f} \sim-T_{e} \log \left(m_{1} / m_{e}\right)^{1 / 2} \sim-4 T_{e}$, so that the electron current collected is only a few percent $\left(e^{-4} \sim 2^{\prime} \times 10^{-2}\right)$ of the electron saturation level (1/4)ne $\bar{v}_{e} A_{p}$. Only those electrons having an energy greater than about $4 \mathrm{~T}_{e}$ can ever be collected, which makes the double probe inherently poor in accurately determining the electron temperature. In addition, even small departures from a pure Maxwellian electron distribution can greatly influence the current characteristic in the transition region near $V=0$, as described later in the paper.

For a Maxwellian electron distribution, the probe current $I$ as a function of $\mathrm{V}$ is given by

$$
I=I_{+} \tanh \left(V / 2 T_{e}\right)
$$

The ion saturation current $i_{+}$is given by

$$
1_{+}=\frac{1}{4} \operatorname{ne}\left(8 \mathrm{kT}_{\mathrm{e}} / \mathrm{m}_{1}\right)^{1 / 2 \mathrm{~A}}
$$

where $A$ is the effective collection area that differs from the probe area $A_{p}$ by a constant factor $\gamma$ of order unity, which is determined from Laframboise's orbital theory. ${ }^{3}$ A represents the area of the sheath surrounding each of the probe wires. It is a function of $v$, but for typical gun plasmas, the Debye length is much smaller than the wire radius so that $\gamma$ is always close to unity. From Laframboise, ${ }^{3}$ assuming $T_{1}=T_{e}$ because typical equipartition times are approximately a few microseconds, we find $\gamma=1.8$, almost independent of $\mathrm{V}$. For $\mathrm{T}_{\mathrm{e}}=6 \mathrm{eV}, 1_{+}=1.0, \mathrm{~A}$ corresponds to an ion density of $5 \times 10^{14} \mathrm{~cm}^{-3}$, using Eq. (2) for deuterium with $A_{p} \sim 10^{-2} \mathrm{~cm}^{2}$.

Magnetic field effects can be ignored ${ }^{4}$ for large values of $V$ for which ion saturation current is collected because the typical ion gyro-radius is much greater than the sheath radius $(\gamma)^{1 / 2} r_{p}$. However, for small values of $v$, where electron collection is substantial, magnetic effects will alter somewhat 
the ideal characteristic given by Eq. (1) and cause further uncertainty in the determination of $\mathrm{T}_{\mathbf{e}}$.

IV. EXPERIMENTAL RESULTS

First, some miscellaneous checks on the probe and the circuit of Fig. 1(a) were performed. $V$ was measured at the circuit box and between the tips, resulting in identical values for the two cases. No current was drawn when the probe was outside the flux conserver with voltage applied, so that no stray currents resulted from the gun or snipper coll firings. The collected current was not sensitive to probe rotation, which ensures that there is no appreciable contribution from the time-varying magnetic flux in the unshielded area between the leads of the probe tips. On one shot, $V$ was reversed to $-50 \mathrm{~V}$, and the collected current was reversed (as compared to the case $\mathrm{V}=50 \mathrm{~V}$ ), which was expected for this symmetrical probe. No obvious damage to the probe was ever noticed and the plasma properties observed independently did not seem to be appreclably different when the probe was inserted or withdrawn from the flux conserver.

The current characteristic as a function of $V$ was obtained on several occasions at a fixed location and time. This was done by varying $V$ between shots, and the results are shown in Fig. 2. Curves Fig. 2(a) and Fig. 2(b) contain data obtained at $x=2.5 \mathrm{~cm}$ (near the wal1) at $40 \mu \mathrm{s}$ and $100 \mu \mathrm{s}$, respectively, after the gun firing. Curve Fig. 2(c) shows the characteristic obtained at $x=20 \mathrm{~cm}$ (center of flux conserver), 125 us after the gun firing. For this latter position, characteristics obtained between 50 and $200 \mu$ are nearly identical to the one presented in Fig. 2(c). The curves of Fig. 2 are similar to each other and strongly depart from the ideal curve for a Maxwellian electron distribution given by Eq. (1). We note a strong current depression for $\mathrm{V}$ less than about $30 \mathrm{~V}$ by comparison with the hyperbolic tangent shape and the absence of a well-defined ion saturation level that one would expect for the thin sheath experimental situation. It is shown in the Appendix that a slight departure from a Maxwellian can explain the characteristics of Fig. 2. More precisely, for example, a tenuous-fast component of density $\sim 0.4 \%$ of the bulk plasma density and temperature $\sim 500 \mathrm{eV}$ is sufficient to qualitatively reproduce the characteristic of Fig. 2(c). For this case, the bulk plasma temperature was estimated at $6 \mathrm{eV}$ (average Thomson scattering data at $125 \mu \mathrm{s}$ ). Of course, other non-Maxwe11ian features such as 


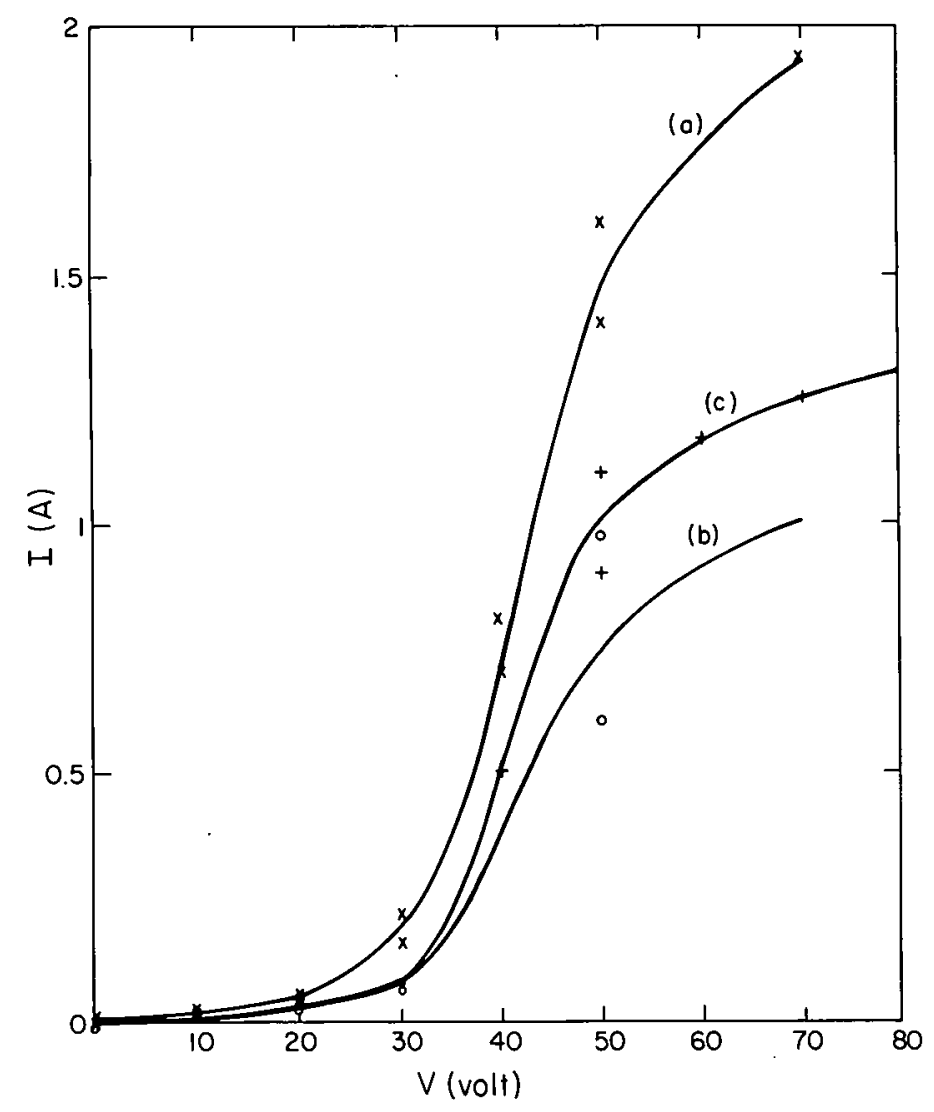

$\mathrm{Fig} \cdot 2$

Current characteristics as a functions of $\mathrm{v}:$ (a) $\mathrm{x}=2.5 \mathrm{~cm}$, $t=40 \mu \mathrm{s},(\mathrm{b}) \mathrm{x}=2.5 \mathrm{~cm}, t=100 \mu \mathrm{s}$, and (c) $x=20 \mathrm{~cm}$ and $t=125$ us. $t=0$ corresponds to the gun firing.

"bump-on-the-tail" or drifts ${ }^{2-5}$ could also account for the curves of Fig. 2. This gives us some confidence that the probe data are meaningful. Furthermore, the same double probe and electrical circuit have been used on a preionized (by theta-pinch ringing) plasma, which yielded ideal characteristics [e.g., Eq. (1)] .

It is shown in the Appendix that the slope of the current characteristic around $\mathrm{V}=40 \mathrm{~V}$ may still be indicative of the bulk plasma temperature within a factor of 2. For the case of Fig. 2(c), this corresponds to about $10 \mathrm{eV}$. One can estimate the ion saturation current of this case at about $0.7 \mathrm{~V}$. This corresponds to a density of $7 \times 10^{14} \mathrm{~cm}^{-3}$, using Eq. (2) for deuterium with $\gamma=1.8$ and a temperature of $6 \mathrm{eV}$. At $10 \mathrm{eV}$, the corresponding density would be about $5 \times 10^{14} \mathrm{~cm}^{-3}$. The uncertainties associated with the electron temperature, the saturation level, and the collection area make the density 
value uncertain within about a factor of 2. Earlier interferometry data ${ }^{6}$ gave an average density of about 2 to $4 \times 10^{14} \mathrm{~cm}^{-3}$, in reasonable agreement with the above probe data.

A plasma spatial profile as a function of $\mathrm{x}$ was obtained, shot by shot, for a fixed value of $V=50 \mathrm{~V}$. Figure $3(\mathrm{a})$ shows a typical current trace as a function of time, obtained at $x=15 \mathrm{~cm}$; the current level settles to a value of about $1 \mathrm{~A}(.5 \mathrm{~V})$ within $50 \mu \mathrm{s}$ of the gun firing and remains at that leve1 for about $200 \mu \mathrm{s}$, a feature that was observed with minor variations for most of the data used for the spatial profile. We chose to plot the profile at $100 \mu \mathrm{s}$ after the gun firing and these data are given in Fig. 4. We note that

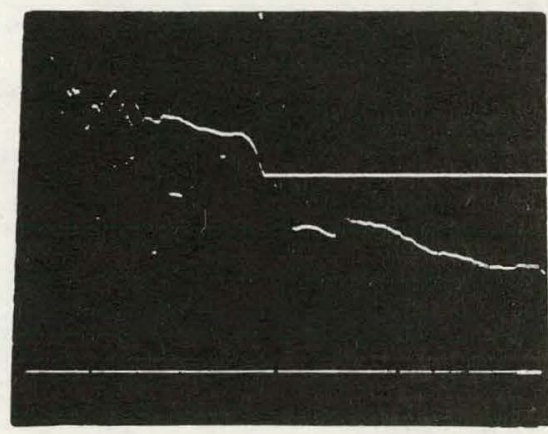

\section{]0.5v \\ ] $0.2 v$}

(a)
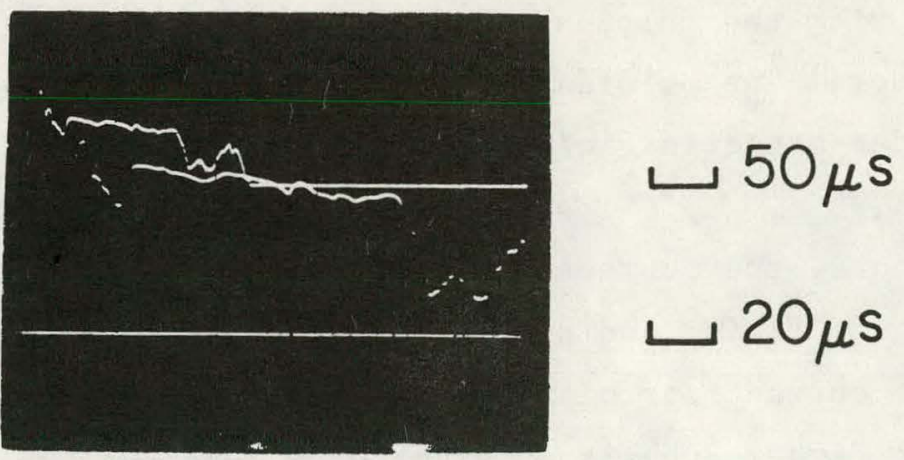

(b)

Fig. 3

Current traces as a function of time for $\mathrm{V}=50 \mathrm{~V}$ : (a) shot 1569 at $\mathrm{x}=15 \mathrm{~cm}$ and (b) shot 1558 at $\mathrm{x}=5 \mathrm{~cm}$. 


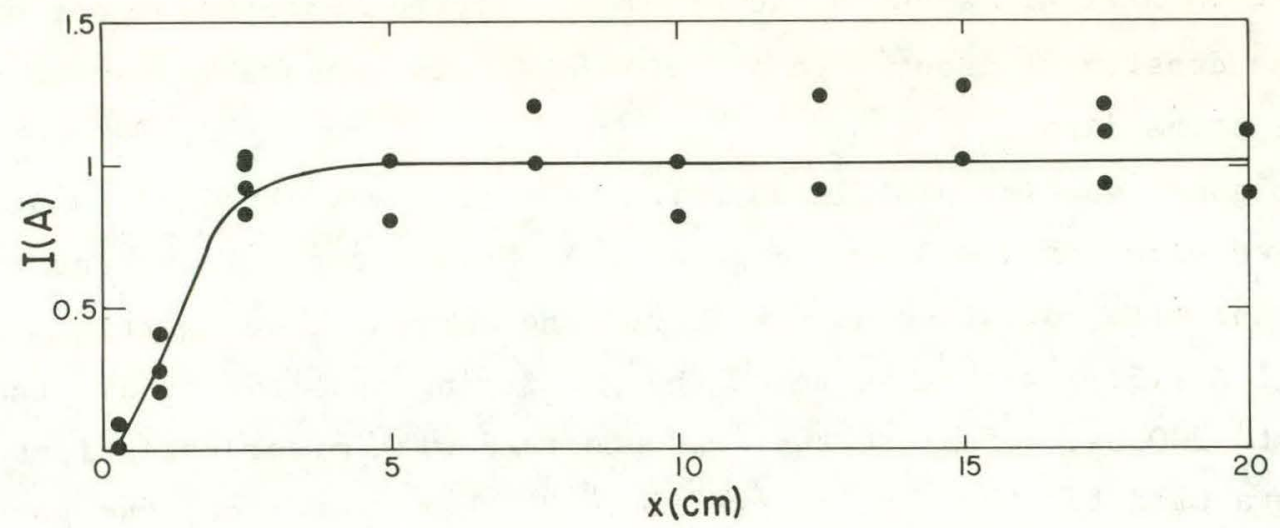

Fig. 4

Spatial current (I) profile as a function of distance $x$.

the density profile is remarkably flat over most of the range of $x$, except for an abrupt density drop for $x$ less than $2 \mathrm{~cm}$. As mentioned previously, no noticeable current was drawn with the probe pulled just outside the aperture in the flux conserver. The lowest measurable density is about $10^{12} \mathrm{~cm}^{-3}$, which corresponds to a few millivolts on the oscilloscope.

The collected current is observed to be approximately constant in time, up to about $200 \mu$ s after the gun firing. There is a relatively sharp current drop to zero level within the last $50 \mu \mathrm{s}$, as seen for example in Fig. 3(a). The initial higher current level can be interpreted in terms of mass motion or higher temperature. The total probe-current lifetime correlates well (within better than $5 \%$ ) with the poloidal magnetic field lifetime near the top wa11 of the flux conserver. The poloidal field lifetime is defined by the time at which the poloidal magnetic field reverses sign, that is, when the 0 point has reached the wall.

For most shots, the current fluctuation level is $\geqslant 20 \%$ for the first $100 \mu \mathrm{s}$ after gun firing and drops to a few percent at later times. In some cases, quiescent current periods greater than $100 \mu$ s in duration are observed at early times. Figure $3(b)$ is an example of such data.

These experimental results, in particular the characteristics of Fig. 2, are consistent with the results obtained with a symmetric double probe on the Livermore gun experiment. 7 
Additional data were obtained with a solid copper flux conserver instead of the previous stainless steel flux conserver. Similar plasmas were probed $\left(\mathrm{n} \sim 5 \times 10^{14} \mathrm{~cm}^{-3}, \mathrm{~T}_{\mathrm{e}} \sim 10 \mathrm{eV}\right)$. The longer magnetic field penetration time of the copper she11 prevented the rapid plasma decay previously observed. around $250 \mu \mathrm{s}$, and the plasma 11fetime was extended to about $400 \mu \mathrm{s}$, in agreement with magnetic probe and interferometry (He-Ne; $3.39 \mu$ ) data. The plasma and magnetic field lifetimes are defined as the times for the probe current and magnetic field to reach zero level, respectively. Following an experiment performed at Livermore, ${ }^{7}$ a glass shield was mounted on one side of the probe so that data could be taken with the double probe shielded (or not shielded) from a given direction. For these experiments the probe was inserted at a distance $y$ from the side of the flux conserver as indicated on Fig. 1(b). Near the top of the flux conserver (for small values of $y$ ), the plasma current is presumably mostly pololdal (opposite to the direction of the poloidal flux lines for this experiment). At $y=5 \mathrm{~cm}$, two probe characteristics were obtalned, shot by shot, and are displayed in Fig. 5 for $t=125 \mu \mathrm{s}$ after the gun firing. Curve Fig. 5(a) was obtained with the shield rotated to block the pololdal current (ion current blocked, electron current unblocked) whereas curve Fig. 5(b) was obtained with the shield rotated by $180^{\circ}$. This latter characteristic is quite similar to those previously obtained [e.g., Fig. 2(c)], with a strong current depression around $\mathrm{V}=30 \mathrm{~V}$, whereas the characteristic of Fig. 5(a). is closer to the Ideal hyperbolic tangent curve expected for a double probe from a pure Maxwellian plasia.

So far, no definite conclusion has been obtained from those results, which suggest some anisotropy in the plasma velocity distribution. The most plausible explanation for the depressed characteristics mentioned previously is the presence of a component of fast electrons. However, the results shown in Fig. 5 would suggest a fast electron current which unexpectedly opposes the net plasma current. As yet, this discrepancy has not been resolved. 


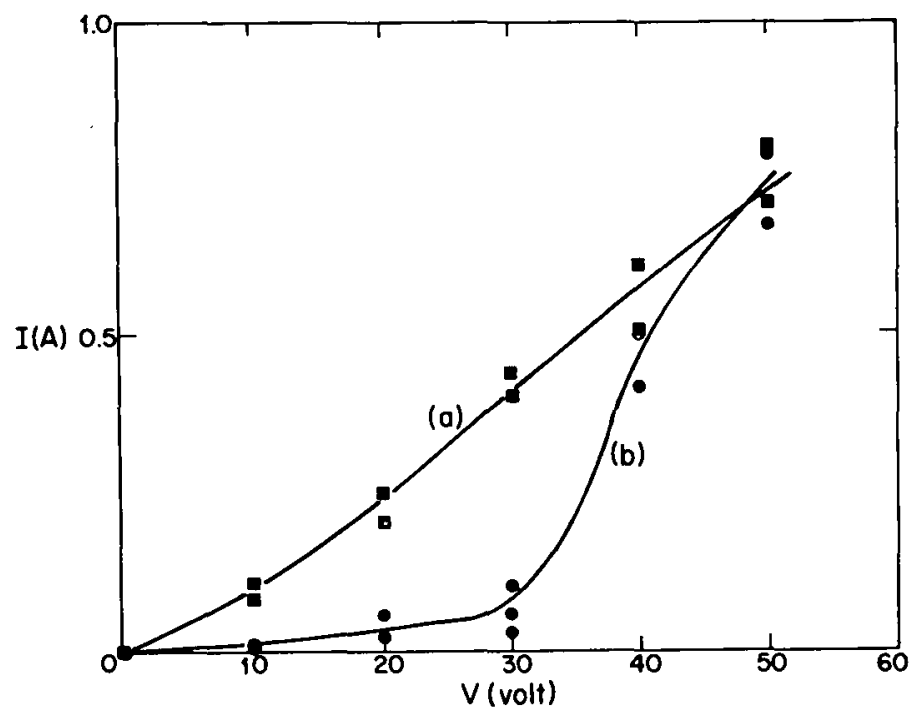

Fig. 5

Current characteristics for a shielded double probe at $y=5 \mathrm{~cm}$ and $t=125 \mu \mathrm{s}$ : (a) plasma current blocked; (b) plasma current unblocked.

\section{CONCLUSIONS}

The preliminary results obtained with a double Langmuir probe in the CTX facility confirm the existence of a gun plasma of density of about $5 \times 10^{14} \mathrm{~cm}^{-3}$ and temperature $\leqslant 10 \mathrm{eV}$ lasting for about 250 to $400 \mu \mathrm{s}$. The values for the density and the temperature should be accurate to within a factor of about 2. These results are in agreement with interferometry and Thomson scattering data. The probe exhibits current characteristics as a function of voltage that suggest non-Maxwellian features of the particles distribution functions and that can be qualitatively modeled with a tenuous-fast electron component. There is some experimental evidence that the velocity distribution functions might involve drift velocities. The plasma density appears fairly constant for most of the plasma lifetime and a spatial scan indicates a flat density profile up to the flux conserver boundary. Large fluctuation levels of $220 \%$ are observed, in particular during the first $100 \mu \mathrm{s}$, but at later times, fluctuation levels of less than a few percent are observed on most shots. Although of a qualitative nature for the most part, the information that might be gleaned from such a simple diagnostic appears to easily justify the modest investment of time and capital it required. 


\section{ACKNOWLEDGEMENTS}

I wish to thank Dan Prono, Tom Jarboe, and Ivars Henins for helpful experimental advice and several members of the Compact Torold Program for useful criticism of this manuscript. I also gratefully acknowledge the skilled technical assistance of Ernie Newmąn.

\section{REFERENCES}

1. E. Johnson and L. Malter, "A Floating Double Probe Method for Measurements In Gas Discharges," Phys. Rev. 80, 58 (1950).

2. F. F. Chen, in Plasma Diagnostic Techniques, R. H. Huddlestone and

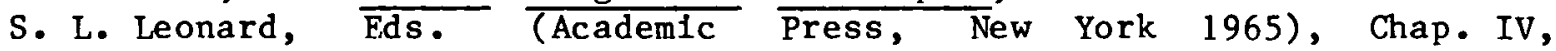
pp. 178-183.

3. J. G. Laframboise, Univ. of Toronto Inst. for Aerospace Studies report UTIAS-100 (1966).

4. I. G. Brown, A. B. Compher, and W. B. Kunke1, "Response of a Langmu1r Probe in a Strong Magnetic Field," Phys. Fluids 14, 1377 (1971).

5. I. Langmuir and H. M. Mott-Smith, "The Theory of Collectors in Gaseous D1scharges," Phys. Rev. 28, 727 (1926).

6. T. R. Jarboe, I. Henins, H. W. Holda, R. K. Linford, J. Marshall, D. A. Platts, and A. R. Sherwood, "Motion of a Compact Toroid Inside a Cylindrical Flux Conserver," Phys. Rev. Lett. 45, 1264 (1980).

7. W. C. Turner, G. C. Goldenbaum, E. H. A. Granneman, C. W. Hartman, D. S. Prono, J. Taska, and A. C. Smith, "Formation of Compact Torolda1 Plasmas by Magnetized Coaxial Plasma Gun Injection into an Oblate Flux Conserver," Third Symposium on Physics and Technology of Compact Toroids in the Magnetic Fusion Energy Program, Los Alamos, New Mexico, Dec. 2-4, 1980; Los Alamos Nationa1 Laboratory Report LA-8700-C (1981), P. 113.

\section{APPENDIX}

\section{DOUBLE PROBE CHARACTERISTIC FOR A BI-MAXWELLIAN ELECTRON DISTRIBUTION}

We assume a plasma with an electron distribution consisting of two Maxwellians. A bulk plasma of density $\mathrm{n}_{\mathrm{a}}$ and temperature $\mathrm{T}_{\mathrm{a}}$ and a tenuous-hot component, respectively of density $n_{b}\left\langle\left\langle n_{a}\right.\right.$ and temperature $T_{b} \gg T_{a}$. The ion distribution is assumed to be a Maxwellian with density $n_{1} \sim n_{a}$ and temperature $T_{a}$. We assume that $\alpha=\left(n_{b} / n_{a}\right)\left(T_{b} / T_{a}\right)^{1 / 2}$ is much-1ess than unfty, 
so that the ion saturation current is given by Eq. (2) with $n=n_{a}$ and $\mathrm{T}_{e}=\mathrm{T}_{\mathrm{a}}$. At $\mathrm{V}=0,\left(\mathrm{~V}_{1}=\mathrm{V}_{2}=\mathrm{V}_{\mathrm{f}}\right)$, neglecting magnetic field effects, the electron current $1_{-}$is given by

$$
1_{-}=\frac{1}{4} e A_{p}\left(n_{a} \bar{v}_{a} e^{V_{f} / T_{a}}+n_{b} \bar{v}_{b} e^{V_{f} / T_{b}}\right),
$$

where $\bar{v}=\left(8 \mathrm{kT}_{e} / \mathrm{m}_{e}\right)^{1 / 2}$ for each of the two components and $v_{f}$ is the floating potential with respect to the space potential. For $V=0$, the floating condition $i_{+}=1_{-}$becomes

$$
\frac{\gamma}{\left(m_{1} / m_{e}\right)^{1 / 2}}=e^{V_{f} / T_{a}}+\alpha e^{V_{f} / T_{b}}
$$

We now assume that for $v>0, v_{1}=v_{f}+\frac{V}{2}$ and $v_{2}=v_{f}-\frac{V}{2}$ rather than solving the exact potential problem. This approximation should yleld some qualitative answer, although it clearly breaks down for $V \sim V_{f}$. The probe current I can then be expressed as a function of $\mathrm{V}$ with

$$
I=1_{+}+\frac{e^{V_{f} / T_{a}} \sinh \left(\frac{V}{2 T_{a}}\right)+\alpha e^{V_{f} / T_{b}} \sinh \left(\frac{V}{2 T_{b}}\right)}{e^{V_{f} / T_{a} \cosh \left(\frac{V}{2 T_{a}}\right)+\alpha e^{V_{f} / T_{b}} \cosh \left(\frac{V}{2 T_{b}}\right)}} .
$$

For $\alpha=0$, Eq. (A-3) reduces to Eq. (2) as expected. Given $T_{a}, T_{b}$, and $n_{b} / n_{a}$, Eqs. $(A-2)$ and $(A-3)$ can be used to find the characteristic. For $\gamma=1.8$ and $\left(m_{i} / m_{e}\right)^{1 / 2}=60$, the value of the left-hand side of $E q \cdot(A-2)$ is $3 \times 10^{-2}$. For the cases of interest where $T_{b} \gg T_{a}$ and $\alpha<<1$, solutions for $V_{f}$ from Eq. (A-2) are obtained with $e^{V_{f} / T_{a}} \gg 1$ and $e^{V_{f} / T_{b}} \sim 1$. We further observe from $E q$. (A-3) that, for small values of $V, I / 1_{+}+\tanh \left(V / 2 T_{b}\right) \sim V / 2 T_{b}$ so that the slope of the current characteristic as $\mathrm{V} \rightarrow 0$ is indicative of the fast component temperature $T_{b}$. This reflects the fact that, for small values of $v, v_{1}$ and $v_{2}$ are both strongly negative with respect to the space potential and that only a few electrons on the tail of the electron distribution 
function can be collected (e.g., primarily those of the hot component). For large values of $V\left(e . g ., V \gg T_{a}\right)$, the dominant contribution in Eq. (A-3) comes from sinh $\left(\mathrm{V} / 2 \mathrm{~T}_{\mathrm{a}}\right) \sim \cosh \left(\mathrm{V} / 2 \mathrm{~T}_{\mathrm{a}}\right) \sim(1 / 2) \mathrm{e}^{\mathrm{V} / 2 \mathrm{~T}} \mathrm{a}$, and the probe current $\mathrm{I}$ tends towards the saturated level $i_{+}$. At intermediate values of $V$ (e.g., $\left.\mathrm{T}_{\mathrm{a}}<\mathrm{V} \ll \mathrm{T}_{\mathrm{b}}\right)$, the exponential character of the hyperbolic sine and cosine of argument $\mathrm{V} / 2 \mathrm{~T}_{a}$ begins to compensate for the small value of $e^{V_{f}} / \mathrm{T}_{a}$ and the current characteristic experiences a fairly rapid change of slope between the two asymptotic values discussed previously. In this intermediate range of $v$, when the hyperbolic sine and cosine of argument $\mathrm{V} / 2 \mathrm{~T}$ a begin to dominate, $\mathrm{I} / \mathrm{i}_{+} \rightarrow \tanh \left(\mathrm{V} / 2 \mathrm{~T}_{\mathrm{a}}\right)$ so that the slope of the characteristic could still provide a factor of 2 approximation of the bulk plasma temperature $T_{a}$.

We now consider the experimental data of Fig. 2(c). This characteristic is reproduced in Fig. A-1(a); from the current slope at low values of $\mathrm{V}$, one can estimate $T_{b}$ at about $500 \mathrm{~V}$. We assume $T_{a}=6 \mathrm{eV}$ from the average Thomson scattering data. Figure $\mathrm{A}-1(\mathrm{~b})$ shows the 1 deal curve of $\mathrm{I} / \mathrm{i}_{+}$corresponding to Eq. (2) or Eq. (A-3) with $\alpha=0$. Figure A-l(c) shows the characteristic obtained for $\alpha=0.034$. With $\mathrm{T}_{\mathrm{a}}=6 \mathrm{eV}$ and $\mathrm{T}_{\mathrm{b}}=500 \mathrm{eV}$, this corresponds to $v_{f}=-4.3 V$ and $n_{b} / n_{a} \sim 4 \times 10^{-3}$. One observes from Figs. A-1(b) and A-1(c) that even a tenuous-fast component is sufficlent to drastically modify the current characteristic in qualitative agreement with the experimental data of

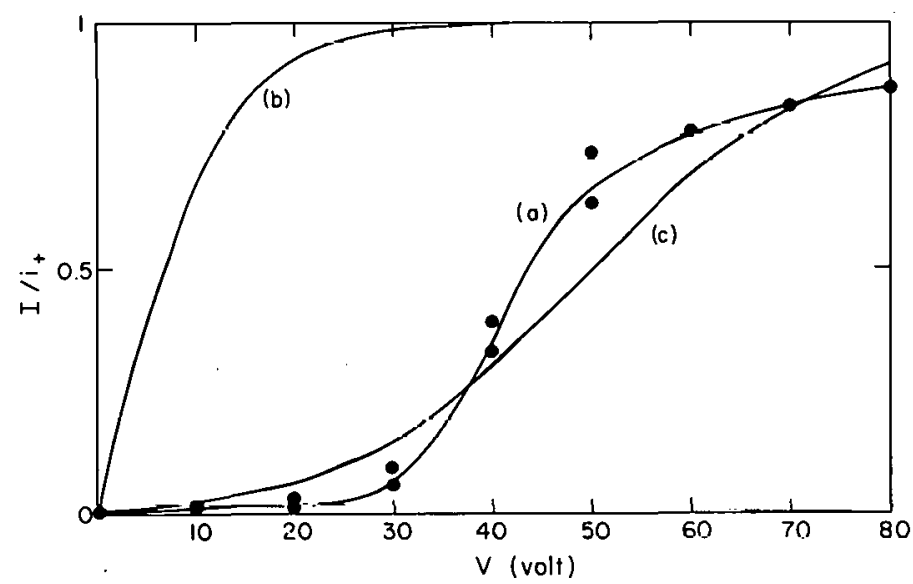

Fig. A-1

Comparison of current characteristics: (a) experimental data at $\mathrm{x}=20 \mathrm{~cm}$ and $t=125 \mu \mathrm{s}$, (b) ideal characteristic for $\alpha=0$, and (c) characteristic for $\alpha=0.034$. 
Fig. A-1(a). We note that the slope of the curve Fig. 5(a) near $V \sim 40 \mathrm{~V}$ is approximately equal to the slope of the curve Fig. A-1(b) at low values of $V$. As suggested previously, one can still estimate the bulk temperature $\mathrm{T}_{\mathrm{a}}$ to about $10 \mathrm{eV}$ from the experimental data, with $\left[\mathrm{d}\left(\mathrm{I} / \mathrm{i}_{+}\right) / \mathrm{dV}\right]_{\mathrm{V}=40 \mathrm{~V}} \sim \mathrm{V} / 2 \mathrm{~T}_{\mathrm{a}}$. 


\begin{tabular}{|c|c|c|c|c|c|c|c|c|c|c|c|}
\hline \multirow[b]{2}{*}{ Page Range } & \multicolumn{7}{|c|}{$\begin{array}{l}\text { Printed in the United States of America } \\
\text { Available from } \\
\text { National Technical Information Service } \\
\text { US Department of Commerce } \\
5285 \text { Port Royal Road } \\
\text { Springfield, VA } 22161\end{array}$} & \multirow{2}{*}{\multicolumn{2}{|c|}{$\begin{array}{c}\text { NTIS } \\
\text { Price Code } \\
\end{array}$}} & \multirow[b]{2}{*}{$\begin{array}{c}\text { Domestic } \\
\text { Price }\end{array}$} & \multirow[b]{2}{*}{$\begin{array}{c}\text { NTIS } \\
\text { Price Code }\end{array}$} \\
\hline & $\begin{array}{c}\text { Domestic } \\
\text { Price } \\
\end{array}$ & $\begin{array}{c}\text { NTIS } \\
\text { Price Code } \\
\end{array}$ & Page Range & $\begin{array}{c}\text { Domestic } \\
\text { Price } \\
\end{array}$ & $\begin{array}{c}\text { Microfiche } \\
\text { NTIS } \\
\text { Price Code } \\
\end{array}$ & Page Range & $\begin{array}{c}\text { Domestic } \\
\text { Price } \\
\end{array}$ & & & & \\
\hline $001-025$ & $\$ 5.00$ & $\mathrm{~A} 02$ & 151.175 & $\$ 11.00$ & A08 & $301-325$ & $\$ 17.00$ & A 14 & $451-475$ & $\$ 23.00$ & $\mathrm{~A} 20$ \\
\hline $026-050$ & 6.00 & $\mathrm{AOU}_{3}$ & $176-200$ & 12.00 & AUY & $326-350$ & 18.00 & A 15 & 476.500 & 24.00 & $A 21$ \\
\hline $051-075$ & 7.00 & $\mathrm{~A} 04$ & $201-225$ & 13.00 & $\mathrm{~A} 10$ & $351-375$ & 19.00 & A 16 & $501-525$ & 25.00 & A 22 \\
\hline $076-100$ & 8.00 & AUS & $226-250$ & 14.00 & Al1 & $376-400$ & 20.00 & A 17 & $526-550$ & 26.00 & A 23 \\
\hline $101-125$ & 9.00 & A06 & $251-275$ & 15.00 & $\mathrm{~A} 12$ & $401-425$ & 21.00 & A 18 & 551.575 & 27.00 & A 24 \\
\hline $126-150$ & 10.00 & $\mathrm{~A} 07$ & $276-300$ & 16.00 & $\mathrm{~A} 13$ & $426-450$ & 22.00 & A 19 & $576-600$ & 28.00 & A 25 \\
\hline
\end{tabular}


